\title{
Efficient risk determination of risk of road blocking by means of MMS and data of buildings and their surrounding
}

\author{
Kazuhito Nose,Shuhei Hatake \\ (kaz.nose,sh.hatake)@ajiko.co.jp \\ Commission I Topics of Special Sessions(Sps) \\ SpS13 - FIG:The Surveyors'Response to City Management
}

Department of West Japan Geospatial Information,Asia Air Surbey,29F OAP Tower 1-8-30 Tenmabashi Kita-ku,OsakaJapan

KEY WORDS: MMS、Inspection indices of Road blocking、Combined technologies of geospatial survey and GIS and alleviating field Survey

\begin{abstract}
:
Massive earthquake named "Tonankai Massive earthquake" is predicted to occur in the near future and is feared to cause severe damage in Kinki District. "Hanshin-Awaji Massive Earthquake" in 1995 destroyed most of the buildings constructed before 1981 and not complying with the latest earthquake resistance standards. Collapsed buildings blocked roads, obstructed evacuation, rescue and firefighting operations and inflicted further damages.To alleviate the damages, it is important to predict the points where collapsed buildings are likely block the roads and to take precautions in advance. But big cities have an expanse of urban areas with densely-distributed buildings, and it requires time and cost to check each and every building whether or not it will block the road. In order to reduce blocked roads when a disaster strikes, we made a study and confirmed that the risk of road blocking can be determined easily by means of the latest technologies of survey and geographical information.
\end{abstract}

\section{INTRODUCTION}

During the years of steep economic growth in Japan, infrastructure was upgraded to improve standard of living of the nation and wealthy lives of the people were realized. . Housing shortage has been resolved and enough housing stock has been built. However, in big cities densely-built wooden house areas were formed where the houses built at the time do not comply with the latest earthquake resistance standards. And it is feared that collapsed building will obstruct the vehicles for emergency operations when a disaster occurs.

The Great East Japan Earthquake in 2011 caught the world's attention to the damages caused by tsunami. On the other hand as shown in Fig. 1, in case of the Hanshin Massive Earthquake occurred directly under the urban area in 1995, serious damages were caused not by tsunami but by the roads blocked by collapsed buildings in dense residential areas, rendering them impassable for emergency vehicles for rescue and fire fighting and consequently further damage was inflicted.

Nankai Trough Massive Earthquake predicted to occur within 30 years with probability of $70 \%$ is feared to destroy 940 thousand to 2.4 million buildings and create serious obstacles on road networks.

Inspection indices of road blocking are related intricately to road width, building height, materials used for building, year of construction and others. Priority has been given to investigate roadsides of emergency transport route but as for local roads maintained by provincial governments, the investigation has been limited to field survey of assumed area of road blocking due to time and budgetary constraints. And it is neither efficient nor practical to acquire such data because of enormous volume of the stock (total length of roads).

In view of the situation we selected an urban inland area of a big city that is unlikely to be hit by tsunami and studied a method to determine the risk visually and efficiently by combined technologies of geospatial survey and GIS and with reduced field survey work.

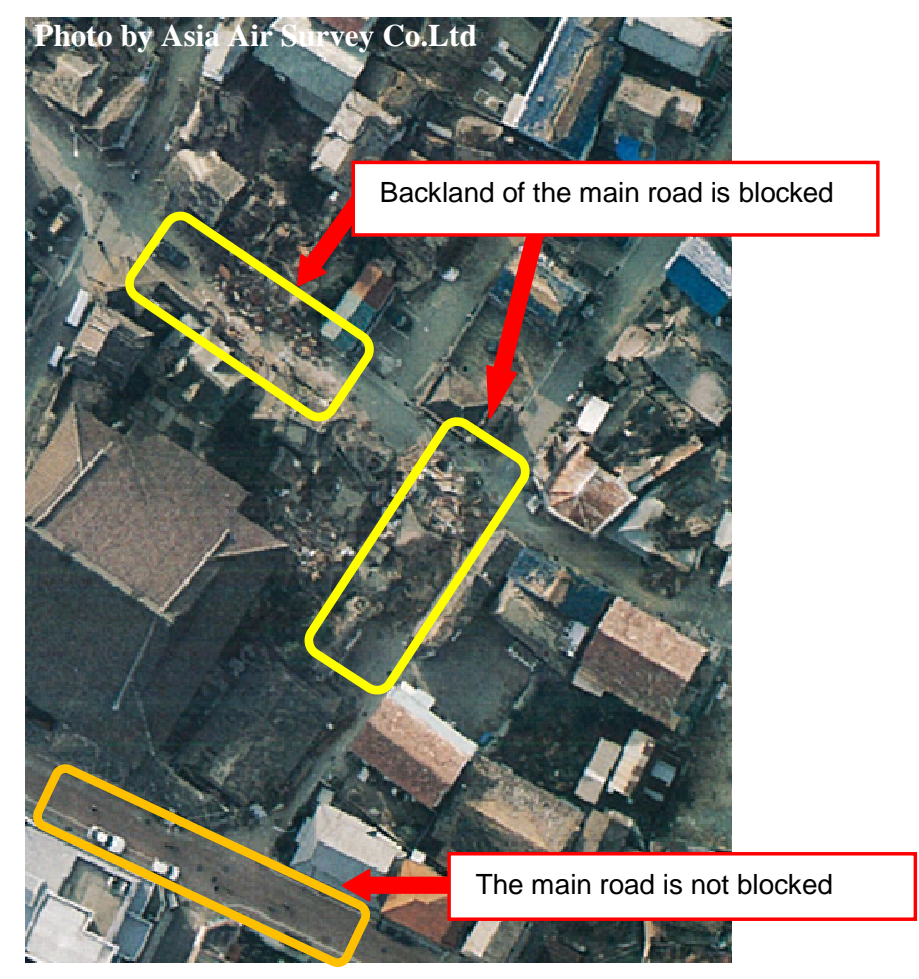

Figure.1 Roads blocked by Hanshin-Awaji Massive Earthquake

\section{STUDY ON ASSESSMENT CRITERIA}

Likelihood of road blocking is assessed based on the risk of collapse of buildings which will obstruct traffic of emergency vehicles and evacuation of a district.

The roads which will play important role to evacuate a great number of people and to transport goods in case of a disaster are 
defined as "Emergency Transport Route" by the plan of local governments under Act for Promotion of Renovation for Earthquake-Resistant Structures and the buildings taller than a certain height along the route are supposed to be renovated for enhanced earthquake safety.

- Criterion1: If frontal road width is more than $12 \mathrm{~m}$ :

The buildings with height exceeding $1 / 2$ of road width

- Criterion2: If frontal road width is $12 \mathrm{~m}$ or less: The buildings with height of $6 \mathrm{~m}$ or more

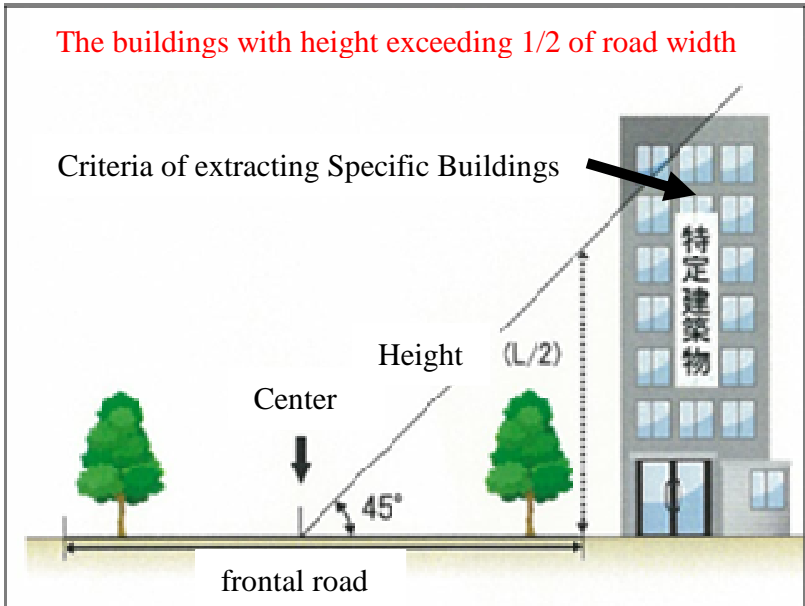

Figure.2 Criteria of extracting Specific Buildings to be renovated

Mostly the roads of $10 \mathrm{~m}$ or more in width are secured for Emergency Transport Route and they are not likely to get entirely impassable even after the buildings along the road have collapsed.

But old wooden houses along small lanes in the back land (called "Residential Roads") are likely to collapse and may block the roads rendering the area inaccessible by emergency vehicles.

The risk of road blocking is extremely high in Japan where old wooden houses are densely located but no criteria of determining the risk have been prepared yet.

To assess quantitatively the risk of blocking Residential Roads, we decided to acquire the following additional information to as supplemental criteria and study them, in addition to the 450 Elevation Angle from the centre line of the road as shown in Fig.2.

- Supplement Criterion 1: Year of construction, Structure, Usage

- Supplement Criterion 2: Details of road and priority

Based on the above criteria, we studied to determine the risk of blocking roads other than Emergency Transport Route in dense urban areas.

\section{ACQUISITION/CREATION OF POINT GROUP BY MMS}

In May 2012, Geographical Survey Institute of Japan issued "Manual for Creating Digital Mapping Data by means of
Mobile Mapping System (MMS)" and its technology and application have spread nationwide since then.

The survey vehicle as in Fig. 3 runs along a road at about 50 $\mathrm{km} / \mathrm{h}$ and radiate laser and acquire positions and shapes of the building along the roads as high density laser 3D point group data. The system has an advantage not to disturb traffic on the roads because the vehicle runs at a normal travelling speed while acquiring the data.

These data enable to measure accurately (1) Distance between the road and the building, (2) Height of the building, and (3) Road width. In this study, the survey vehicle of Table 1 was used to run in an urban area and acquired laser point group data.

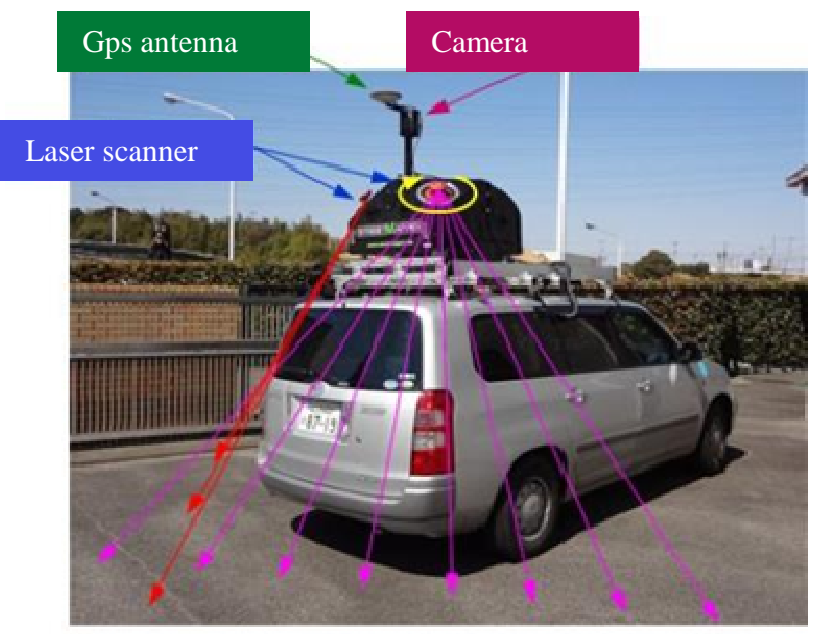

Figure3. MMS Vehicle

Table 1 Specification of Measuring Vehicle

\begin{tabular}{|l|l|}
\hline \multicolumn{1}{|c|}{ Items } & \multicolumn{1}{|c|}{ Specification } \\
\hline Vehicle & $\begin{array}{l}\text { Vehicle mounted with GNSS/IMU, } \\
\text { odometer, digital camera and laser } \\
\text { scanner }\end{array}$ \\
\hline GNSS analysis & $\begin{array}{l}\text { Capable of post processing } \\
\text { kinematic analysis based on } \\
\text { electronic control point }\end{array}$ \\
\hline Image resolution & $\begin{array}{l}\text { Whole circumference camera of } \\
5400 \mathrm{x} 2700 \text { pixels }\end{array}$ \\
\hline Image spacing & $3 \mathrm{~m}$ or less \\
\hline $\begin{array}{l}\text { Laser point group } \\
\text { density }\end{array}$ & $\begin{array}{l}400 \text { points/m2 or more on the road } \\
\text { for mapping }\end{array}$ \\
\hline $\begin{array}{l}\text { Laser distance } \\
\text { measuring accuracy }\end{array}$ & $1 \mathrm{~cm}$ or less \\
\hline $\begin{array}{l}\text { Laser distance } \\
\text { measuring range }\end{array}$ & $\begin{array}{l}50 \mathrm{~m} \text { or more in whole } \\
\text { circumference }\end{array}$ \\
\hline $\begin{array}{l}\text { Attributes of laser } \\
\text { point groups }\end{array}$ & $\mathrm{X}, \mathrm{Y}, \mathrm{Z}$ reflection intensity \\
\hline Measuring speed & $\begin{array}{l}\text { Normal travelling speed which } \\
\text { does not disturb public vehicles and } \\
\text { without traffic control }\end{array}$ \\
\hline
\end{tabular}

Examples of the data acquired:

(1)Distance from road edge to building

(2) Buildings exceeding elevation angle of 450 from road centre line

(3) Road width 


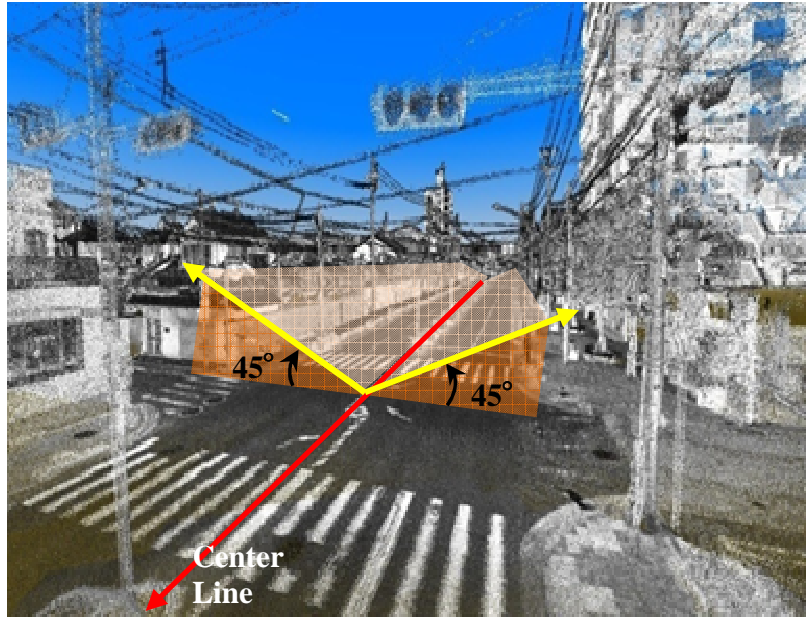

Figure.4 Measurement by high density laser 3D point group

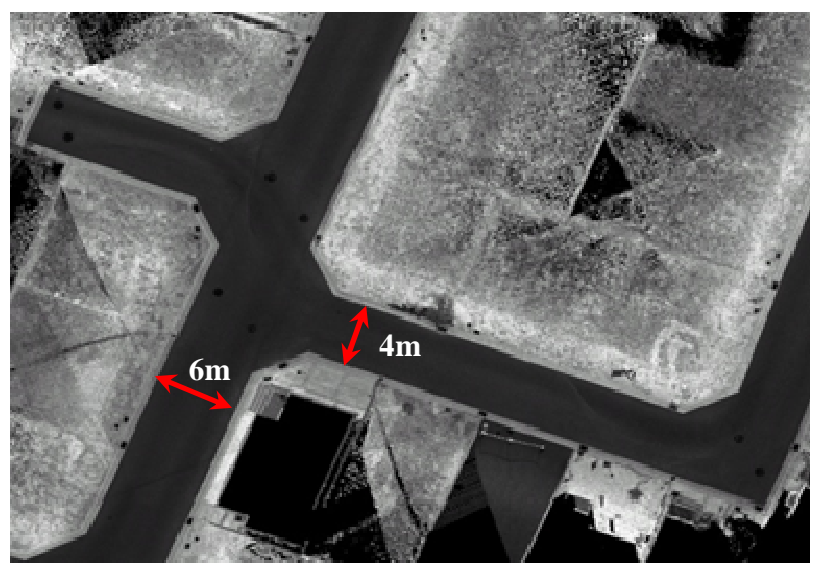

Figure.5 Measurement of road width on road surface orthoimage

The elevation angle of 450 from the centerline of the road was created automatically The buildings which exceed this angle were extracted as the candidates to block roads. Conventionally building height was measured with survey equipment on site, but it can now be measured more easily and accurately by using MMS data.

Highly accurate road width was measured on a PC by creating orthophoto image of road surface from laser 3D point group data.

\section{RECOGNITION OF DETAILS OF BUILDINGS}

We studied the data stored by taxation department of the city government to check quake resistance of the houses in the city and to identify the houses which may collapse when a disaster occurs.

For the purpose of taxation on fixed assets most city governments have the database of land and buildings, and also Lot Number Situation Map and Building Situation Map as well.
When the Building Situation Map is processed by means of GIS, information of a desired building like the year of construction and structure of the building can be easily acquired.

Because roads are closely related to daily lives of the residents, we added the indices from a) to d) of Table 2 below, which can be acquired by GIS processing of Building Situation Maps, in addition to the criteria of Fig. 2 and tried to determine risk in the order of gravity of the risk.

Table 2 Building and road indices

\section{a) Index I}

Date of construction: Whether it is before or after 1995 Judgment of aging

b) Index II

Structure of building: Wooden, Non-wooden, RC (rigid), Others

\section{c) Index III}

Classification of building: Fire protection district, Semi fire protection district, Others

d) Index IV

Road conditions: Road width, Sidewalk, Continuity of road

For each of these indices, we further set up detailed classification (Table 3 and 4) and ? ? ? (Table 6), and prepared differential rate (Fig. 7) by statistical analysis of Mathematical Quantification Theory Class I in order to calculate probability of road blocking quantitatively. In the statistic calculation, probability of road blocking was calculated for each building by simulation system.

Table 3 Examples of additional indices (Road condition: Road width)

\begin{tabular}{|ll|l|l|}
\hline & & Classification & \multicolumn{1}{|c|}{ Judgment } \\
\hline Rank & A & 6m or more & $\begin{array}{l}\text { Probability of road blocking: } \\
\text { Low }\end{array}$ \\
\hline Rank & B & Less than 6m & $\begin{array}{l}\text { Probability of road blocking: } \\
\text { Rather low }\end{array}$ \\
\hline Rank & C & Less than 4m & 4m reference value \\
\hline Rank & D & Less than 3m & $\begin{array}{l}\text { Probability of road blocking: } \\
\text { Rather high }\end{array}$ \\
\hline Rank & E & Less than 2m & $\begin{array}{l}\text { Probability of road blocking: } \\
\text { High }\end{array}$ \\
\hline
\end{tabular}

Table 4 Examples of additional indices (Building condition)

\begin{tabular}{|c|c|c|}
\hline & $\begin{array}{c}\text { Risk } \\
\text { classification }\end{array}$ & Basis of judgment \\
\hline Rank A & Not dangerous & \\
\hline Rank B & $\begin{array}{l}\text { Rather not } \\
\text { dangerous }\end{array}$ & $\begin{array}{l}\text { Date of construction } \\
\text { Type of building structure }\end{array}$ \\
\hline Rank C & Ordinary & Classification of building \\
\hline Rank D & $\begin{array}{c}\text { Rather } \\
\text { dangerous }\end{array}$ & \\
\hline Rank E & Dangerous & \\
\hline
\end{tabular}




\begin{tabular}{|c|c|c|c|c|c|}
\hline 要因№.: 21 & $\begin{array}{l}\text { Condition : } \\
\text { Name }\end{array}$ & Road conditions & & \multicolumn{2}{|c|}{ : Road width, } \\
\hline category & \multicolumn{5}{|c|}{ LessThan $2 \mathrm{~m}$ LessThan $3 \mathrm{~m}$ LessThan $4 \mathrm{~m}$ LessThan $6 \mathrm{~m} 6 \mathrm{~m}$ Or More } \\
\hline LessThan $2 \mathrm{~m}$ & 0.0 & -6.1 & -8.0 & -8.9 & -9.8 \\
\hline LessThan 3m & 6.5 & 0.0 & -2.0 & -3.0 & -3.9 \\
\hline LessThan $4 \mathrm{~m}$ & 8.7 & 2.0 & 0.0 & -1.0 & -2.0 \\
\hline LessThan $6 \mathrm{~m}$ & 9.8 & 3.1 & 1.0 & 0.0 & -1.0 \\
\hline 6m Or More & 10.9 & 4.1 & 2.0 & 1.0 & 0.0 \\
\hline
\end{tabular}

Figure.6 Simulation System Screen

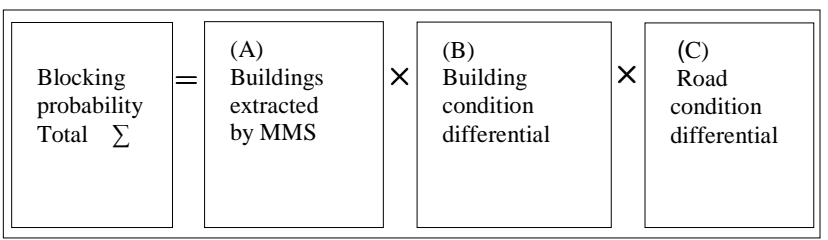

Figure.7 Total differential rate calculation

\section{VISUALIZATION ON GIS}

All these integrated information were visualized by means of GIS to show the buildings likely to collapse. Verification tests were made in a sample area with narrow roads and many wooden houses.

We confirmed that much more buildings will collapse when only (a) Building extraction by MMS is considered than when (B) Road condition and (C) Building condition are added.

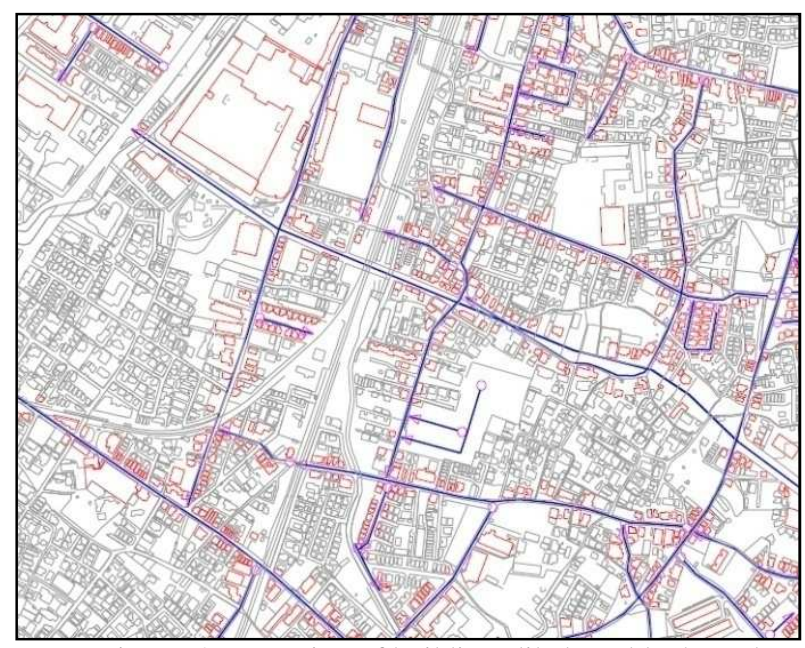

Figure. 8 Extraction of buildings likely to block roads (Blue lines: Roads studied Red squares: Buildings likely to block roads)

Then we gave information multiplied by (B) Building condition differential and (C) Road condition differential to attributes of buildings, visualized it by GIS and rechecked the distribution blocked roads.

We divided the city into multiple areas and obtained the ratio of total length of likely blocked roads against total length of roads in the area as an index.

In Area A, for example, this ratio exceeded $60 \%$ when buildings were extracted from MMS data only (in other words, when only positional relation road and building is considered). But it reduced to $44 \%$ and then to $15 \%$ when road condition differential and then building condition differential were added and the locations of blocked roads were identified also. (Table.5)

Table 5 Ratio of blocked roads in each area

\begin{tabular}{|c|c|c|c|}
\hline & $\begin{array}{c}\text { Extracted } \\
\text { by MMS }\end{array}$ & $\begin{array}{c}\text { Road } \\
\text { conditions } \\
\text { are added }\end{array}$ & $\begin{array}{c}\text { Building } \\
\text { and road } \\
\text { conditions } \\
\text { are added }\end{array}$ \\
\hline $\begin{array}{c}\text { Extraction } \\
\text { level }\end{array}$ & $\mathrm{A}$ & $\mathrm{B}$ & $\mathrm{C}$ \\
\hline \hline Area A & $62 \%$ & $44 \%$ & $15 \%$ \\
\hline Area B & $70 \%$ & $39 \%$ & $13 \%$ \\
\hline
\end{tabular}

Fig. 9 shows the roads in Area A visualized by GIS. Coloured buildings (in Red, Blue and Yellow) are extracted by Level A of Table 5.

When Level B was applied as additional conditions to extract, the buildings in blue disappeared. Then when Level C condition was applied, buildings in yellow disappeared and only the buildings in red remained as dangerous buildings. In other words, priority must be given to the buildings in red when performing emergency operations in case of a disaster.

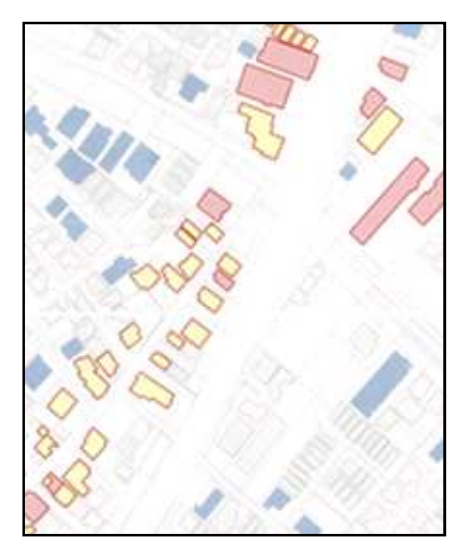

Figure.9 Extraction of buildings likely to block roads

\section{CONCLUSION}

When extracting road blocking probability, we studied the models to calculate considering elements of roads and buildings. Although actual cases of roads blocked by collapsed buildings are not enough to quantify the risk of road blocking, it is possible to quantify the probability of road blocking and assess the risk easily without site investigation, by using the latest survey technology and information of buildings stored by various organizations. However patterns of road blockings do not rely only on the value calculated as above because it is also influenced by manner of quake and shape of buildings. It is necessary to take into consideration the people who cannot reach a safety evacuation area due to the road rendered impassable by a disaster.

Since temporary gathering shelters are designated by local governments in each district, it is possible to visualize alternative routes to such shelters bypassing the roads which may be blocked by collapsed buildings. The damages of a disaster will be alleviated if the risk of impassable road is shown to the public in advance.

\section{ACKNOWLEDGEMENTS (OPTIONAL)}

I would like to express my sincere gratitude to those who cooperated with me to make this report. 